\title{
Article
}

\section{Patient-centred outcomes for prehospital trauma trials: A systematic review and patient involvement exercise}

Hancox, James M, Toman, Emma, Brace-McDonnell, Samantha J and Naumann, David N

Available at http://clok.uclan.ac.uk/25773/

Hancox, James M, Toman, Emma, Brace-McDonnell, Samantha J and Naumann, David N (2019) Patient-centred outcomes for prehospital trauma trials: A systematic review and patient involvement exercise. Trauma, 21 (4). pp. 259-271. ISSN 1460-4086

It is advisable to refer to the publisher's version if you intend to cite from the work. http://dx.doi.org/10.1177/1460408618817912

For more information about UCLan's research in this area go to http://www.uclan.ac.uk/researchgroups/ and search for <name of research Group>.

For information about Research generally at UCLan please go to http://www.uclan.ac.uk/research/

All outputs in CLoK are protected by Intellectual Property Rights law, including Copyright law. Copyright, IPR and Moral Rights for the works on this site are retained by the individual authors and/or other copyright owners. Terms and conditions for use of this material are defined in the policies page.

\section{CLoK}

Central Lancashire online Knowledge www.clok.uclan.ac.uk

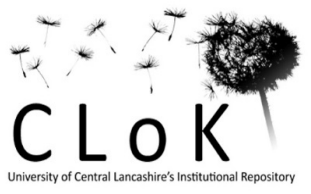




\section{Patient-centred outcomes for prehospital trauma trials: a systematic review and patient involvement exercise}

\begin{tabular}{|c|c|}
\hline Journal: & Trauma \\
\hline Manuscript ID & TRA-18-0043.R1 \\
\hline Manuscript Type: & Original Article \\
\hline Keywords: & Trauma, Prehospital, Patients, Trials, Outcomes, Research \\
\hline Abstract: & $\begin{array}{l}\text { Introduction } \\
\text { Outcome measures are used in clinical trials to determine efficacy of } \\
\text { interventions. } \\
\text { We aimed to determine which outcome measures in prehospital major } \\
\text { trauma trials have been reported in the literature, and which of these are } \\
\text { most patient-centred. } \\
\text { Methods } \\
\text { A systematic review identified outcomes reported in prehospital clinical } \\
\text { trials of major trauma patients. A search was undertaken using Medline, } \\
\text { Embase, clinicaltrials.gov, Web of Science and Google Scholar. Data } \\
\text { were summarized by dividing outcomes into common themes. These } \\
\text { were presented to a Patient and Public Involvement (PPI) group } \\
\text { consisting of trauma survivors and their relatives. This group ranked the } \\
\text { categories of outcomes in order of most importance, and to agree some } \\
\text { consensus statements regarding these outcome measures. } \\
\text { Results } \\
\text { There were } 27 \text { eligible studies, including } 9,537 \text { patients. Outcome } \\
\text { measures were divided into } 9 \text { categories: quality of life (QoL); length of } \\
\text { stay; mortality/survival; physiological parameters fluid/blood product } \\
\text { requirements; complications; health economics; safety and feasibility; } \\
\text { and intervention success. Of these, mortality/survival was the most } \\
\text { common reported category, but in multiple timescales. The PPI group } \\
\text { agreed that the most important category was QoL, and that } \\
\text { mortality/survival should only be reported if concurrently reported with } \\
\text { longer term QoL. Length of stay and health economics were not } \\
\text { considered important. } \\
\text { Conclusions } \\
\text { Outcome measures in prehospital clinical trials in major trauma have } \\
\text { been heterogeneous, inconsistent, and not necessarily patient-centred. } \\
\text { Trauma survivors considered QoL and mortality most important when } \\
\text { combined. Consensus is required for consistent, patient-centred, } \\
\text { outcome measures in order to investigate interventions of meaningful } \\
\text { impact to patients. }\end{array}$ \\
\hline
\end{tabular}

\section{SCHOLARONE Manuscripts}


Table 1. Patient characteristics from included studies

\begin{tabular}{|c|c|c|c|c|c|c|}
\hline Author & Year & Country & Age & $\%$ male & ISS & $\begin{array}{l}\text { MOI (\% blunt } \\
\text { trauma) }\end{array}$ \\
\hline Baker & 2009 & Canada (Toronto) & 42.5 & 60 & 36.2 & \\
\hline Baxt & 1987 & USA (San Diego) & 27.8 & & 13.9 & 100 \\
\hline Bernard & 2010 & Australia (Melbourne) & 40 & 75 & 30.5 & 100 \\
\hline Bickell & 1985 & USA (Houston) & & & & 17.1 \\
\hline Bickell & 1987 & USA (Houston) & & & 22.5 & 0 \\
\hline Bickell & 1994 & USA (Houston) & 31 & 88 & 26 & 0 \\
\hline Bulger & 2008 & USA (Seattle) & 41 & 62.7 & 28 & \\
\hline Bulger & 2010 & USA (Seattle) & 38.9 & 76.3 & 26.9 & 98.6 \\
\hline Bulger & 2011 & USA (Seattle) & 37.7 & 77.3 & 22.8 & 60.9 \\
\hline Chang & 1995 & USA (Wichita) & 34.5 & 77.9 & 25.9 & 48.4 \\
\hline Cooper & 2004 & Australia (Melbourne) & 38 & 66 & 38 & \\
\hline Garner $^{ \pm}$ & 2015 & Australia (Sydney) & $42_{-}^{*}$ & 76 & $26_{-}^{*}$ & \\
\hline Helm et al & 2003 & Germany (Ulm) & 38.4 & 70.2 & 32.2 & \\
\hline Junger & 2013 & USA (Boston) & 39.1 & 86.4 & $25.5_{-}^{*}$ & 95.5 \\
\hline Maningas & 1989 & USA (San Francisco) & 33 & & 16.6 & 0 \\
\hline Mattox & 1989 & USA (Houston) & & & 20 & \\
\hline Mattox & 1991 & USA (Houston) & 34 & 83 & 19 & 26 \\
\hline Moore $e^{ \pm}$ & 2009 & USA (Denver) & 35.9 & 77 & 20.1 & 47 \\
\hline Morrison & 2011 & Canada (Toronto) & 46 & 60 & 31 & 100 \\
\hline Rhee & 1994 & USA (Omaha) & 31 & 75 & & \\
\hline Sayre & 1996 & USA (Cincinnati) & 29 & 95 & 25 & \\
\hline Schreiber & 2015 & USA (Portland) & 41.9 & 75 & $9.5_{-}^{*}$ & 66.7 \\
\hline Turner & 2000 & UK (Sheffield) & & 64.4 & & 98.3 \\
\hline Vassar & 1991 & USA (Sacramento) & $29_{-}^{*}$ & & $27_{-}^{*}$ & 84.3 \\
\hline Vassar & 1993 & USA (Sacramento) & 32 & & 19 & \\
\hline Vassar & 1993 & USA (Sacramento) & 31 & & 32 & \\
\hline Watts & 1999 & USA (Falls Church) & & & 9 & \\
\hline
\end{tabular}

ISS: injury severity score; MOI: mechanism of injury;

Central tendency values for age and ISS are presented exactly as extracted from individual studies, and represent mean values unless indicated with an asterisk as median. Gaps in the table represent unavailable data.

${ }^{ \pm}$Data taken from revised criteria

"From "as treated" data 
Table 2. Outcomes reported in included studies according to individual categories

\begin{tabular}{|c|c|c|c|c|}
\hline & $\begin{array}{l}\text { Number of s } \\
\text { (references) }\end{array}$ & die & & \\
\hline Outcome category & Primary & $\mathbf{N}$ & Secondary & $\mathbf{N}$ \\
\hline Quality of life & & 6 & & 1 \\
\hline Extended Glasgow Outcome Score (6 month) & $(10,15,18,21)$ & 4 & & \\
\hline Glasgow Outcome Score (6 month) & (19) & 1 & & \\
\hline Morbidity (6 month) & $(30)$ & 1 & & \\
\hline Cerebral Performance Category (discharge) & & & (26) & 1 \\
\hline Length of stay & & 7 & & 4 \\
\hline Scene time & (12) & 1 & & \\
\hline Length of stay (in hospital) & $(12,13,17)$ & 3 & $(19,30)$ & 2 \\
\hline Length of stay (intensive care) & $(12,13)$ & 2 & $(19,29)$ & 2 \\
\hline Time in Emergency Centre & $(12)$ & 1 & & \\
\hline Mortality/survival & & 16 & & 11 \\
\hline Non-specified time-frame & $(17,23,33)$ & 3 & $(23,30)$ & 2 \\
\hline 24 hours & (24) & 1 & (25) & 1 \\
\hline 48 hours & & & (26) & 1 \\
\hline 28 days & $(14,16)$ & 2 & $(15,16,21)$ & 3 \\
\hline 30 days & $(24-26)$ & 3 & $(19,25)$ & 2 \\
\hline 6 months & $(30)$ & 1 & & \\
\hline In-hospital & & & (29) & 1 \\
\hline Survival to discharge & $(13,31,32)$ & 3 & (15) & 1 \\
\hline Predicted $v s$ actual survival & $(9,32)$ & 2 & & \\
\hline Time to death & $(12)$ & 1 & & \\
\hline Physiological Parameters & & 8 & & 12 \\
\hline Change in SBP (2 hr period) & $(28)$ & 1 & & \\
\hline Correlation of biomarkers with neurological outcome & $(8)$ & 1 & & \\
\hline Rate of hypotension $(\mathrm{SBP}<90 \mathrm{mmHg})$ & & & $(19)$ & 1 \\
\hline Rate of hypoxia $\left(\mathrm{SpO}_{2}<90 \mathrm{mmHg}\right)$ & & & (19) & 1 \\
\hline Increase in blood pressure & $(31,32)$ & 2 & & \\
\hline Intracranial pressure & & & (15) & 1 \\
\hline Change in temperature during transport & (34) & 1 & & \\
\hline $\mathrm{PaCO}_{2}$ (ED arrival) & $(20)$ & 1 & & \\
\hline Trauma Score (ED arrival) & $(11,12)$ & 2 & & \\
\hline Physiological parameters of organ dysfunction & & & $(15,16)$ & 2 \\
\hline Improvement in physiological status ( 24 hours) & & & (24) & 1 \\
\hline Change in pulse rate & & & $(28)$ & 1 \\
\hline Urinary output & & & (28) & 1 \\
\hline Admission vital signs and blood chemistries & & & (29) & 1 \\
\hline Admission haematologic assays & & & (29) & 1 \\
\hline Renal performance (RIFLE classification) & & & (29) & 1 \\
\hline Change in Triage Revised Trauma Score & & & $(30)$ & 1 \\
\hline Fluid/blood product requirements & & 3 & & 7 \\
\hline Estimated intraoperative blood loss & (13) & 1 & & \\
\hline Perioperative transfusion (units of PRBCs) & (12) & 1 & & \\
\hline Early crystalloid volume & (29) & 1 & & \\
\hline Fluid/blood requirement in first 24 hours & & & $(15,16,29)$ & 3 \\
\hline Fluid/blood requirement & & & (21) & 1 \\
\hline Decreased fluid volume resuscitation requirement & & & (24) & 1 \\
\hline Allogeneic blood use (first 24 hours) & & & $(25)$ & 1 \\
\hline Volume of IV solution administered & & & $(28)$ & 1 \\
\hline Complications & & 0 & & 12 \\
\hline Development of Multi Organ Dysfunction Syndrome & & & $(14)$ & 1 \\
\hline Development of nosocomial infections (28 days) & & & $(14)$ & 1 \\
\hline Development of nosocomial infections & & & $(15,16)$ & 2 \\
\hline Evidence of Infection & & & $(21)$ & 1 \\
\hline
\end{tabular}


Incidence of Multi Organ Failure (30 days)

Multiple Organ Dysfunction Score

$(15,16)$

Reduced post injury complications

Ventilator free days

Any complications

Admission to Intensive Care

\begin{tabular}{|c|c|c|c|}
\hline Health economics & & 1 & 0 \\
\hline Hospital costs & $(12)$ & 1 & \\
\hline Safety and feasibility & & 3 & 2 \\
\hline Adherence to protocol & $(22)$ & 1 & \\
\hline Logistical problems encountered & (22) & 1 & \\
\hline Reported safety issues & (22) & 1 & \\
\hline Safety of interventions & & (24) & 1 \\
\hline Protocol violations & & (29) & 1 \\
\hline Intervention success & & 1 & 1 \\
\hline Intubation success rate & $(27)$ & 1 & \\
\hline Time of intubation & & $(27)$ & 1 \\
\hline
\end{tabular}

SBP: systolic blood pressure; RIFLE: Risk, Injury, Failure, Loss of kidney function, and End-stage kidney disease Studies that report versions of "survival" or "mortality" are grouped together, in subgroups according to timescale. 
Table 3. Primary outcomes reported according to type of intervention

\begin{tabular}{|c|c|c|c|c|c|c|c|}
\hline \multirow[b]{2}{*}{$\begin{array}{l}\text { Primary } \\
\text { Outcome }^{*}\end{array}$} & \multicolumn{7}{|c|}{ Type of intervention } \\
\hline & $\begin{array}{l}\text { Fluid } \\
\text { resuscitation } \\
\text { (hypovolaemia) }\end{array}$ & $\begin{array}{l}\text { Fluid } \\
\text { resuscitation } \\
\text { (TBI) }\end{array}$ & $\begin{array}{l}\text { Anti- } \\
\text { shock } \\
\text { garment }\end{array}$ & $\begin{array}{l}\text { Grade } \\
\text { of } \\
\text { clinician }\end{array}$ & $\begin{array}{l}\text { Prehospital } \\
\text { intubation }\end{array}$ & $\begin{array}{l}\text { Ventilation } \\
\text { strategy }\end{array}$ & $\begin{array}{l}\text { Temperature } \\
\text { management }\end{array}$ \\
\hline Quality of life & (30) & $(15,18,21)$ & & (19) & (9) & & \\
\hline Length of stay & (13) & & $(12,17)$ & & & & \\
\hline Mortality/survival & $\begin{array}{l}(14-16,24,25 \\
30-33)\end{array}$ & (26) & $(17,23)$ & (9) & & & \\
\hline $\begin{array}{l}\text { Physiological } \\
\text { parameters }\end{array}$ & $(31,33)$ & $(8,28)$ & $(11,12)$ & & & (20) & (34) \\
\hline $\begin{array}{l}\text { Fluid/blood } \\
\text { product } \\
\text { requirement }\end{array}$ & $(13,29)$ & & (12) & & & & \\
\hline $\begin{array}{l}\text { Health } \\
\text { economics }\end{array}$ & & & (12) & & & & \\
\hline $\begin{array}{l}\text { Safety and } \\
\text { feasibility }\end{array}$ & $(22)$ & & & & & & \\
\hline $\begin{array}{l}\text { Intervention } \\
\text { success }\end{array}$ & & & & & & & \\
\hline
\end{tabular}


Table 4. Consensus statements made by the group after discussion, summarised for each category of outcome measure.

\section{Outcome measure Consensus statements}

Mortality and

survival

Quality of life

Complications

Safety $\&$ feasibility

Physiological

parameters

Intervention

success

Fluid/blood product requirements

Length of stay

Health economics
Mortality/survival should only be reported if it is also accompanied by a measure of longer term quality of life outcome

This is the most important outcome measure to us

It is important to know the number and seriousness of complications, especially infections

These are important but should not be the main focus of a study

These parameters are only important if they affect the treatment of patients

We consider this important for clinical trials

These parameters are only important if they affect the wellbeing of patients

This is of little importance. We are more interested in the success of treatments than how long is spent in hospital

Cost is not considered important to individuals, but is an important factor for society 
Records identified through database searching $(n=991)$

Additional records identified through other sources

$$
\text { = 991) }
$$$$
(n=7)
$$
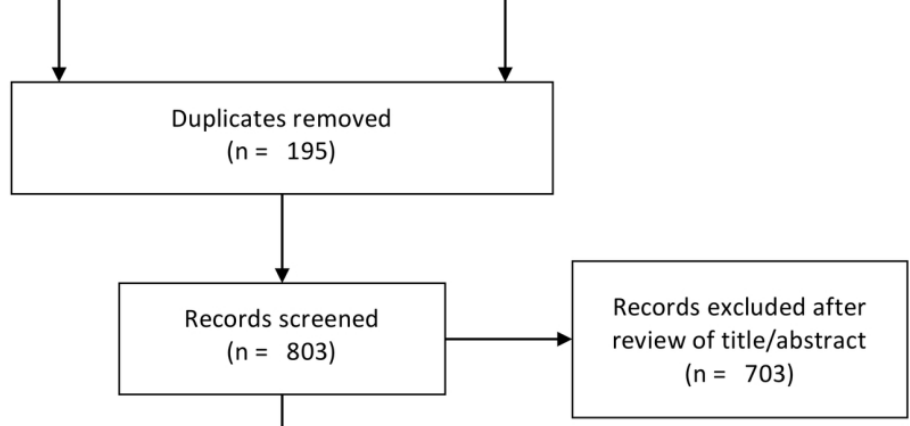

Full-text articles assessed for eligibility $(n=100)$

Full-text articles excluded

$$
(n=73)
$$

Reason for exclusion:

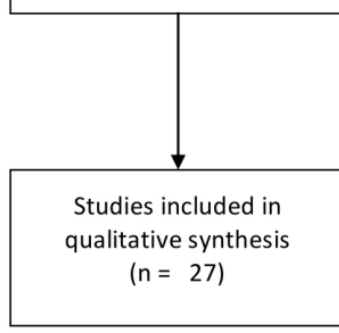

Patient cohort not Major Trauma ( $n=28)$

Inappropriate Study Methodology ( $\mathrm{n}=6$ )

Patient cohort not pre-hospital $(n=14)$

Review/Abstract/Letter ( $n=13)$

No new data $(n=7)$

Protocol/Study Design ( $n=5$ )

Fig 1. PRISMA diagram of search results

$156 \times 148 \mathrm{~mm}(300 \times 300$ DPI $)$ 
Outcome categories shown in rank order according to the Patient and Public Involvement group consensus, with median individual ranks also illustrated (interquartile ranges are shown as horizontal bars around the median)

$184 \times 118 \mathrm{~mm}(300 \times 300$ DPI $)$ 


\section{Supplementary Table 1. Example of Medline database using OVID SP search strategy}

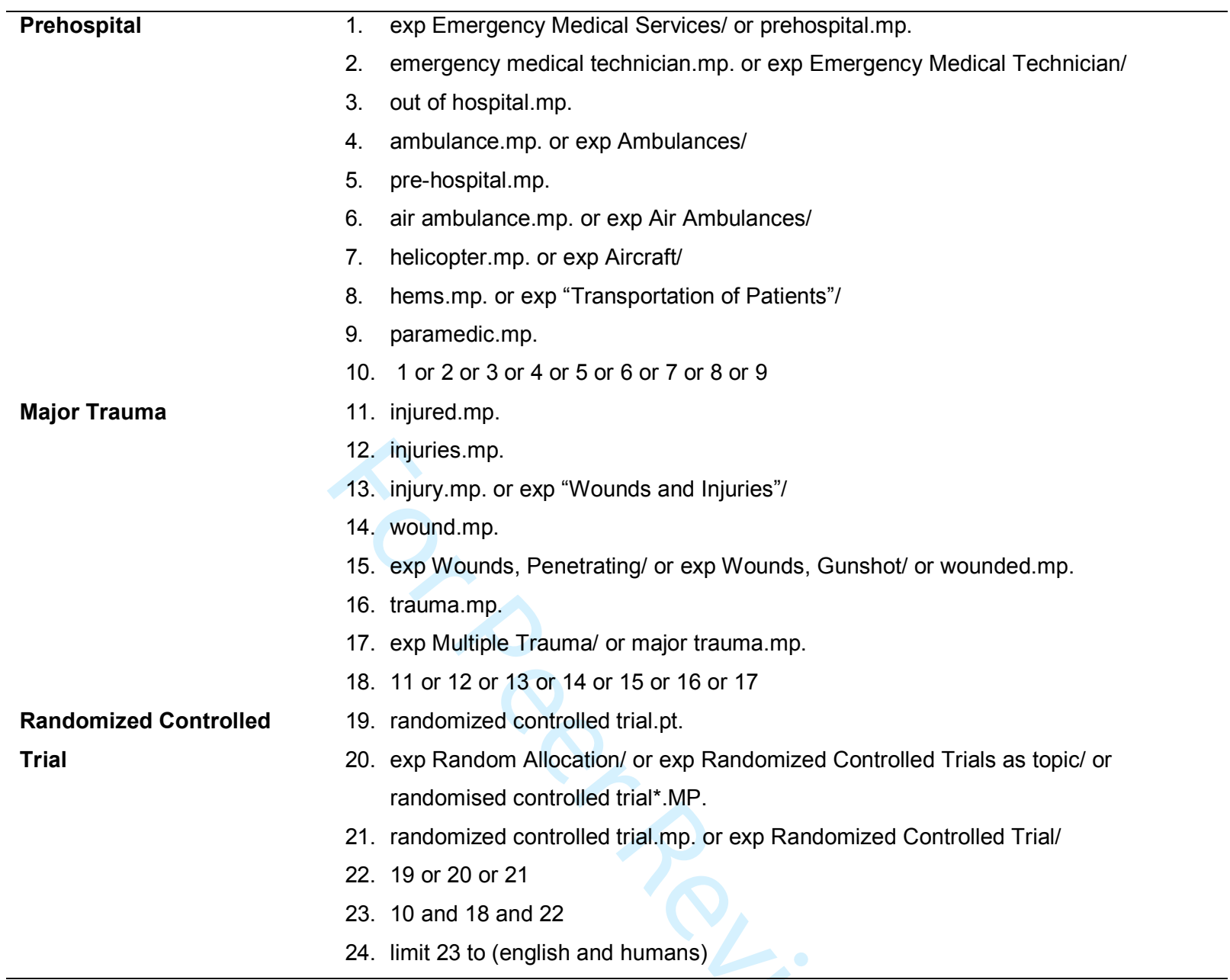




\title{
Patient-centred outcomes for prehospital trauma trials: a systematic review and patient involvement exercise
}

\author{
Running title: patient-centred prehospital trauma trials
}

\begin{abstract}
Introduction

Outcome measures are used in clinical trials to determine efficacy of interventions. We aimed to determine which outcome measures in prehospital major trauma trials have been reported in the literature, and which of these are most patient-centred.
\end{abstract}

\section{Methods}

A systematic review identified outcomes reported in prehospital clinical trials of major trauma patients. A search was undertaken using Medline, Embase, clinicaltrials.gov, Web of Science and Google Scholar. Data were summarised by dividing outcomes into common themes which were presented to a Patient and Public Involvement (PPI) group consisting of trauma survivors and their relatives. This group ranked the categories of outcomes in order of most importance, and agreed consensus statements regarding these outcome measures.

\section{Results}

There were 27 eligible studies, including 9,537 patients. Outcome measures were divided into nine categories: quality of life (QoL); length of stay; mortality/survival; physiological parameters fluid/blood product requirements; complications; health 
economics; safety and feasibility; and intervention success. Of these, mortality/survival was the most commonly reported category, but over multiple timescales. The PPI group agreed that the most important category was QoL, and that mortality/survival should only be reported if concurrently reported with longer term QoL. Length of stay and health economics were not considered important.

\section{Conclusions}

Outcome measures in prehospital clinical trials in major trauma have been heterogeneous, inconsistent, and not necessarily patient-centred. Trauma survivors considered QoL and mortality most important when combined. Consensus is required for consistent, patient-centred, outcome measures in order to investigate interventions of meaningful impact to patients. 


\section{Introduction}

Major trauma is the leading cause of death in the UK of people aged under 40 , with over 20,000 cases and 5,400 deaths every year [1]. Research that aims to improve trauma patient outcomes may be undertaken during the prehospital period, so that earlier interventions, closer to the point of wounding can be investigated. A register of studies in prehospital trauma care [2], concluded that there was a paucity of Randomised Controlled Trials (RCTs) in this setting, and there have been calls for further prehospital research because of the deficit of high quality evidence [3]. Outcome measures reported in RCTs measure the difference in effects between interventions and controls and must be both biologically appropriate and clinically meaningful in order to assess the overall effect of any intervention, and should be selected based on what can be answered given the selected study design and methodology [4]. Furthermore, outcome measures should be patient-centred so that they have a translatable value on patients' lives after injury, treatment and rehabilitation.

The Trauma Audit Research Network (TARN) collects data relating to patients suffering major trauma across England and Wales. It states that "outcomes (survival or death) after trauma are best measured by the number of those who actually survived compared with the number who are expected to survive". TARN records $30-$ day survival data and when combined with other demographic and clinical variables is used to generate a probability of survival (Ps) to enable comparison of survival outcomes between centres. In addition to survival outcomes, and as part of an extended pilot project, TARN also collects Patient Reported Outcome Measures (PROMs) [5]. There has however been no international consensus on which outcome measures should be reported, and in which circumstances in major trauma 
trials. It is timely therefore, to gain insight into which outcome measures have been reported in the literature so far, and to assess whether these are considered important by trauma patients.

The two , mary research questions for the current study were what outcome measures are reported in prehospital RCTs of major trauma patients and which of these outcome measures are patient-centred? It aimed to answer these questions by using a combination of systematic review methodology and a qualitative focus group exercise involving trauma survivors and their relatives.

\section{Methods}

\section{Study design}

This study was undertaken in two parts. Firstly, a systematic review of the literature was performed in order to find all outcome measures used in prehospital clinical trials involving trauma patients. Secondly, those outcome measures were summarised and presented to a Patient and Public Involvement (PPI) group in order to determine which outcome measures they found to be relevant and important to them. The intention was to determine which commonly reported outcome measures were most patient-centred, in order to inform future study investigators and research centres.

\section{Systematic review of the literature}

A systematic review was undertaken using standard systematic review methodology and the Preferred Reporting Items for Systematic Reviews and Meta-Analyses (PRISMA) guidelines [6]. No meta-analysis was planned, since the systematic 
search was intended to be informative rather than to compare outcomes for any intervention.

\section{Inclusion and exclusion criteria}

The inclusion and exclusion criteria for included studies were decided a priori. Clinical RCTs that included adult major trauma patients (ISS $\geq 16$, or if described as "major trauma")during the prehospital phase of care that reported at least one primary outcome measure were eligible for inclusion. There was no limitation on publication date. Studies who reported data from patients who had sustained "minor trauma" were excluded, as were studies where data was reported exclusively from non-trauma patients or if there was a mixed caseload of trauma and non-trauma where data pertaining to the trauma patients could not be extracted separately. Due to the known marked differences that exist between how children and adults interpret and report on their health [7], studies that included only paediatric patients were excluded. The search was restricted to humanstudies published in English.

\section{Search Strategy}

A search strategy was developed to capture all relevant literature. The Medline and Embase databases were searched using the OVID SP interface; the terms being used for the searches included MeSH terms and also free text terms such as "injury", “injuries”, "injured”, "wound”, “wounds”, "wounded”, "trauma”, "prehospital”, "prehospital”, "Emergency Medical Services", "ambulance”, "outcome”, "endpoint”. Consideration was given to international variations of spelling. Other online resources, including www.clinicaltrials.gov, Web of Science and Google Scholar were also searched for articles not found in the database search. An example of the 
search strategy is given in Supplementary Material 1. The last search was performed on $25^{\text {th }}$ February 2017.

\section{Study Selection}

All titles and abstracts were screened, duplicates removed and full texts were obtained for studies of interest. Eligible studies were identified from reading full texts. Reference lists in appropriate reviews and studies of interest were examined for further potentially eligible studies.

\section{Data Extraction}

Data were extracted from all eligible studies. Study-related data included: the type of intervention investigated; study population under investigation, eligibility criteria; country of origin; first author and year of publication. Patient-related data included: number of patients, injury details (injury severity and mechanism); demographic details (age, gender); primary and secondary outcomes. Reported outcomes were extracted verbatim. The time scale of the outcomes were also recorded (short term, long term, intermediate, or indeterminate). "Short term" outcomes were defined as those that occurred within 30 days of admission, and "long term" outcomes were those that occurred after 6 months, with "intermediate" including all those in between. Time scale was "indeterminate" if no specific timing was mentioned (for example "length of hospital stay" or "survival to discharge").

\section{Patient and Public Involvement (PPI) exercise}

\section{Selection of participants}


Our trauma research unit sponsors an Accident, Burns and Critical Care Patient and Public Involvement (PPI) group in order to facilitate discussions between study investigators and previous patients and their relatives. This group is invited to regular meetings with research staff throughout the year. Some of the patients and relatives in this group joined after being invited following a hospital stay, or participation in a trauma, burns or critical care study. Further members of the group were recruited following similar invitations placed in volunteer newsletters distributed at the NHS Trust. This PPI group was invited to participate in our focus group to discuss trauma outcomes in prehospital clinical trials. This group was considered to be approximately representative of those affected by trauma, including relatives, as well as those who had suffered trauma in the past.

\section{Nominal Group Technique}

For this exercise, basic Nominal Group Technique was used in 5 stages: (1) Introduction and explanation; (2) Silent reflection; (3) Sharing of ideas with the group; (4) Group discussion; and (5) Ranking of items in a voting process. Firstly, we presented the findings of our systematic review to the group in a concise manner, explaining the meaning and relevance of outcome measures that have been reported. These outcomes were divided into categories according to type of outcome measure. Then, participants were given sheets of paper and asked to write down their own views without discussing with the rest of the group. They were asked to (i) put the categories of outcome measures in rank-order of personal importance (with number 1 being the most important); (ii) highlight any outcome measures that were particularly important, or considered completely irrelevant; and (iii) write down what they considered most important to them in terms of outcomes following prehospital 
trauma trials (free text). Each participant was then asked to share their ideas with the rest of the group in turn, and this was followed by a group discussion. At the end of this discussion, the group were asked to vote on the rankings of the trauma outcome categories. The whole exercise was completed in 1 hour, and consensus statements for each outcome measure were recorded by the authors. The age and gender were recorded for all participants.

\section{Data analysis}

Systematic review findings are presented in summative form, with no meta-analysis (no comparison was made between outcomes for any intervention). For the PPI exercise, median assigned rank was calculated for each outcome measure. These are presented in order of median rank, with interquartile range. The free text comments are summarised in themes.

\section{Results}

\section{Systematic search results}

Figure 1 shows the PRISMA diagram for study selection. The initial search yielded 998 studies of which 803 were non-duplicates. After screening titles and abstracts the full texts of 100 studies were examined, identifying 27 articles as eligible having met all inclusion criteria [8-34].

\section{Study characteristics}


The 27 included studies were published between 1985 and 2015 and were all RCTs; 20were from the United States with the remaining seven from Canada $[8,26]$, Australia [10, 18, 19], Germany [20] and the United Kingdom [30]. With a total of 20 different individual first authors. There was a diverse range of sub-groups investigated within the wider major trauma population, but most $(17 / 27(62 \%))$ investigated patients with either traumatic brain injury or haemorrhagic shock.

\section{Patient characteristics}

There were 9,537 patients. All included studies reported no statistically significant difference in the basic demographic details (age, sex, mechanism and severity of injury) of patients between either interventions or controls. Table 1 summarises the patient demographics for all included studies according to the intervention arm of each study.

\section{Study interventions}

All studies compared a specific intervention to a standardised control. Four of the studies investigated two interventions versus a control [15, 16, 21, 33], one tested three interventions [32]; and one tested five against controls [34]. The most commonly investigated intervention was hypertonic saline/dextran $(n=11)$; six studies investigated the use of hypertonic saline ; four studies investigated a variant of the anti-shock garment $[11,12,17,23]$ and two studies investigated the impact of physician-led care compared to paramedic-led care $[9,19]$. However, no other single intervention was investigated by more than one study.

\section{Outcomes reported}


Table 2 details the outcomes reported by all included studies, as reported verbatim; seven $(26 \%)$ exclusively reported short term outcomes, two $(7 \%)$ reported exclusively long term outcomes, and seven (26\%) studies exclusively reported outcomes of an indeterminate length. The remaining 11 studies (41\%) reported outcomes that were assessed over a range of timescales.

\section{Primary Outcomes}

All 27 papers stated at least one primary outcome in their methodology, with eight reporting multiple primary outcomes; overall 32 different and unique outcomes were reported. The most frequently reported individual primary outcome was Extended Glasgow Outcome Score (6 month) in four studies [10, 15, 18, 21], with the remainder of all other outcomes being shared by only 3 or fewer studies. Outcomes relating to mortality and survival were the most commonly reported primary outcomes $(n=16)$, but there were 15 permutations according to timescale, cause and stay in hospital; "survival to discharge" was the most common variation in three $[13,31,32]$. Table 3 illustrates the type of primary outcomes, categorised by the nature of the intervention. It is notable that $10 / 17$ studies that investigated fluid resuscitation strategies in hypotensive major trauma patients reported a variant of mortality as their primary outcome. Similarly, in trials where the intervention was fluid administration for the treatment of traumatic brain injury, half of the primary outcomes reported are a quality of life assessment. No study reported both short and longer term primary outcomes and of the six that did report a long term primary outcome, only three $(50 \%)$ reported a short term secondary outcome.

\section{Secondary Outcomes}


Thirteen studies reported at least one secondary outcome, most commonly related to either physiological parameters $(n=13$ ) or complications $(n=13)$, with fluid/blood requirement in the first 24 hours being the most frequently reported individual secondary outcome $(n=3)$, with the remainder of secondary outcomes only being shared by 2 studies or none at all. None of the included studies reported a long term secondary outcome.

\section{Patient and Public Involvement exercise}

There were 10 members of the PPI group, with a mean age of 59 , and six $(60 \%)$ were female. The outcome measures were divided into nine categories according to the systematic review findings : quality of life; length of stay; mortality/survival; physiological parameters; fluid/blood product requirements; complications; health economics; safety and feasibility; and intervention success. The consensus ranks of the nine outcome categories are shown in Figure 2 with the median and interquartile range of ranks assigned by individual members of the group in stages 2 and 3 of the Nominal Group Technique exercise.

The consensus statements for each outcome category are summarised in table 4. The PPI group agreed that quality of life outcome measures were the most important overall. Where mortality/survival outcome measures are reported, quality of life outcomes should also be reported in order to make the former be meaningful. Although the group agreed that health economics was important for society, when asked about the importance to themselves and their family, they found this aspect of lesser importance. Participants did not express views on any particular outcome measures not already reported by the included studies. 


\section{Discussion}

The main findings from the current study are that there are a wide range of outcome measures reported by clinical trials of trauma patients in the prehospital setting, with mortality/survival being the most common, and that trauma survivors consider this outcome measure important. Quality of life outcome measures were also considered very high in importance amongst our PPI group, who also agreed that such outcomes should be reported in addition to mortality/survival. It is notable that outcome measures related to complications were considered of high importance by trauma survivors, but these were only reported as secondary outcome measures in the studies that we found, with no study reporting these as primary outcome measures (Table 2). A large proportion of included studies reported physiological parameters and length of stay outcomes, which were not considered as important by the PPI group.

Our systematic review found that there is heterogeneity in the selection of both primary and secondary outcomes, and also the time points at which these outcomes are assessed. No single outcome measure was shared by more than four studies, and no single secondary outcome was shared by more than three studies. Even mortality and survival were reported in multiple different permutations according to timescale, cause, and relating to time spent in hospital. This heterogeneity is present even within groups of studies that investigated similar interventions, suggesting that there is limited consensus on the types of outcomes to report for any given intervention, and that perhaps a more consistent approach is warranted. Similar heterogeneity and variation of outcome reporting has been described in studies of cardiac arrest [35] and surgery [36]. There have been published calls for further 
research towards the development of comprehensive outcome measures, developed within an internationally recognised framework, following the work undertaken in other areas of research (stroke, brain injury, multiple sclerosis) where a core set of health outcome measures already exist [37]. The use of a framework (such as the International Classification of Function Disability and Health [38]) for the development of a core set of health-related outcome measures may be crucial in developing consensus in this area. The Core Outcome Measures in Effectiveness Trials (COMET) initiative has been established to find agreement in 'core outcome sets' (COS), which are considered the minimum to be measured and reported for any given condition. It is important during the development of COS to strengthen patient and public engagement in research [39]. Our findings may contribute to such efforts by adding information from patients and public in order to facilitate such a process. If future trial investigators are to agree on 'standard' outcome measures to report for prehospital studies of trauma patients, it would be prudent to consider patient reported outcomes. PROMS are already being collected for elective surgery [40], and such an approach would ensure that the most relevant PROMS were reported for prehospital clinical trials in trauma, and comparable to those PROMS recorded by bodies such as TARN.

Only $11 \%$ of studies reported both a short and long term outcome. Our study suggests there is a lack of a consensus regarding core outcomes and timescales within this patient population. This is notable because our PPI group agreed that they would prefer both short term and long term outcomes reported in such trials, in particular, the combination of mortality outcomes and longer term quality of life outcomes. Prehospital clinical trials that include trauma patients represent a logistic 
challenge, and are difficult to plan and undertake, which may explain the relatively low number of studies identified by our search. Because of this limitation, it is important to answer as many research questions as possible for any give trial in such a setting - including both the shorter and longer term clinical outcomes relevant to patients.

A revised Utstein template published in 2008 aimed to provided consensus in the way data is reported following major trauma by precisely defining certain variables; one such core data variable was survival status, the template proposing a binary outcome of "dead or alive" assessed at the 30 day time point [41]. Yet, despite this recommendation, "survival to discharge" is still the most widely reported mortality and survival-based outcome report in prehospital RCTs of major trauma patients. Since TARN records 30-day survival data for all major trauma patients, studies based in England and Wales should be encouraged to include this readily available information in outcome reporting. The use of mortality and survival as outcome measures are advantageous since they are easy to assess, and this may partly account for the frequency of their use. There is, however, debate as to how sensitive a measure mortality is [42] and, as such, consideration should be given to its use. We recommend that in all circumstances where mortality is listed as a primary outcome, an additional quality of life assessment tool be reported, so that "survival" has a meaningful value to those patients within the study, and can be transferable to clinical practice in a way that is patient-centered. There have been other calls for the use of quality of life outcomes other than mortality [43-45], yet implementation of this practice has been slow and their use is not without risk of bias [46]. Our study serves to illustrate that such an aim might be regarded as patient-centred. 
If we agree that the reporting of quality of life outcomes is patient-centred and important for translatability to clinical practice, the measurement of such outcomes should be of high quality, and with a low drop-out rate of trial participants. One difficulty with obtaining these data may be that patients become lost to follow up, or occasionally cannot be contacted months and years after their hospital treatment [47]. Data may therefore be vulnerable to bias towards those who are more able to respond, or make a visit to the research facility or hospital. Or, conversely, patients who are still within long term rehabilitation facilities may be more easily contacted, biasing the data towards worse functional outcomes. In either circumstance, quality of life data may be less complete, and perhaps less reliable, than those regarding survival. Ongoing research in the UK aims to develop electronic capture of PROMs (ePROMs) in trauma patients [48]. An electronic interface may improve PROM data capture in patients who are able to engage with such a programme, but may exclude patients who do not have access to, or are unable to use a computer.

\section{Limitations}

Our search of the literature excluded paediatric patients, and the PPI group were all adults, and only discussed adult trauma, sothe findings may not necessarily be translatable to the paediatric population. The PPI group was relatively small, and although they all had first-hand experience of trauma and hospital treatment, their opinions may have been biased by some factors in their participation: they all survived their injuries, and had successful treatments that rendered them mobile, stable, and willing to participate in such a group. Our PPI group was older and had a higher percentage of female members that the average trauma population from our 
systematic review. However, we consider it likely that their opinions are representative of the wider community of those affected by trauma, such as patient relatives as well as trauma patients alone. The methods used in the current study are limited in scope, and do not present a comprehensive investigation of the issues presented. However, our findings highlight the broader issues of lack of consensus, and some limitations in patient-centred approach to prehospital research. Further attention may be warranted for specific types of research, and for specific patient populations.

\section{Future Direction}

The current study highlights an inconsistency in outcome reporting in prehospital RCTs of major trauma patients, and the variability in patient-centred outcome measures. This variability includes a sparsity of studies that report both short and longer term outcomes, or a combination of survival and quality of life data - both of which were considered important and appropriate by our PPI group. It may be important for both clinicians and patients that future research looks to specify minimum variations of outcomes and strong, robust assessment methods without limiting assessments $[49,50]$. Research should involve stakeholders including patients, their relatives, those that fund healthcare, make health policy, clinicians and scientific investigators. Designers of prehospital RCTs that include major trauma patients may benefit from a "core" set of outcome measures, using standardised and precisely defined outcome measures on which to base the reporting of their findings, in a manner that is in keeping with initiatives such as COMET [39]. This approach may ensure consistency and comparability of outcome reporting, and support future synthesis of data. Moreover, it will help to ensure the creation of a strong evidence 
base upon which the development of healthcare policy and the evaluation of novel interventions can be based. The focussed approach to establishing standardised outcomes that is proposed here has already been demonstrated in other areas of clinical research, such as in cardiac arrest trials [51]. Investigators of prehospital major trauma may wish to build on the progress in other areas of research and seek consensus on the outcomes reported in prehospital trauma research, including a patient-centred approach.

\section{Acknowledgements}

The authors thank the NIHR Surgical Reconstruction and Microbiology Research Centre and the participating Patient and Public Involvement Group for their assistance in the data collection and focus group exercise.

\section{References}

1. National Audit Office. Major trauma care in England. Report by the Comptroller and Auditor General. 2010. Available from:

\section{https://www.nao.org.uk/report/major-trauma-care-in-england/ Accessed 31 May} 2018.

2. Kwan I, Bunn F, Roberts I, Wentz R. The Development of a Register of Randomized Controlled Trials in Prehospital Trauma Care. Prehospital Emergency Care. 2002;6(1):27-30.

3. World Health Organisation. Prehospital trauma care systems. 2005. Available from: http://apps.who.int/iris/bitstream/10665/43167/1/924159294X.pdf. Accessed 31 May 2018. 
4. Sloan EP, Schlichting AB. Prehospital trauma research methodology. Prehospital Emergency Care. 2002;6(2 Suppl):S68-74.

5. The Trauma Audit and Research Network (TARN). Available from: http://www.tarn.ac.uk/ Accessed 31 May 2018.

6. Moher D, Liberati A, Tetzlaff J, Altman DG. Preferred reporting items for systematic reviews and meta-analyses: The PRISMA statement. International Journal of Surgery. 2010;8(5):336-41.

7. Willis CD, Gabbe BJ, Butt W, Cameron PA. Assessing outcomes in paediatric trauma populations. Injury. 2006;37(12):1185-96.

8. Baker AJ, Rhind SG, Morrison LJ, Black S, Crnko NT, Shek PN, Rizoli SB. Resuscitation with hypertonic saline-dextran reduces serum biomarker levels and correlates with outcome in severe traumatic brain injury patients. Journal of Neurotrauma. 2009;26(8):1227-40.

9. Baxt WG, Moody P. The impact of a physician as part of the aeromedical prehospital team in patients with blunt trauma. JAMA. 1987;257(23):3246-50.

10. Bernard SA, Nguyen V, Cameron P, Masci K, Fitzgerald M, Cooper DJ, Walker T, Std BP, Myles P, Murray L, David, Taylor, Smith K, Patrick I, Edington J, Bacon A, Rosenfeld JV, Judson R. Prehospital rapid sequence intubation improves functional outcome for patients with severe traumatic brain injury: a randomized controlled trial. Annals of Surgery. 2010;252(6):959-65.

11. Bickell WH, Pepe PE, Wyatt CH, Dedo WR, Applebaum DJ, Black CT, Mattox $\mathrm{KL}$. Effect of antishock trousers on the trauma score: a prospective analysis in the urban setting. Annals of Emergency Medicine. 1985;14(3):218-22. 
12. Bickell WH, Pepe PE, Bailey ML, Wyatt CH, Mattox KL. Randomized trial of pneumatic antishock garments in the prehospital management of penetrating abdominal injuries. Annals of Emergency Medicine. 1987;16(6):653-8.

13. Bickell WH, Wall MJJ, Pepe PE, Martin RR, Ginger VF, Allen MK, Mattox KL. Immediate versus Delayed Fluid Resuscitation for Hypotensive Patients with Penetrating Torso Injuries. New England Journal of Medicine. 1994;331(17):1105-9. 14. Bulger EM, Jurkovich GJ, Nathens AB, Copass MK, Hanson S, Cooper C, Liu PY, Neff M, Awan AB, Warner K, Maier RV. Hypertonic resuscitation of hypovolemic shock after blunt trauma: a randomized controlled trial. Archives of Surgery. 2008;143(2):139-48.

15. Bulger EM, May S, Brasel KJ, Schreiber M, Kerby JD, Tisherman SA, Newgard C, Slutsky A, Coimbra R, Emerson S, Minei JP, Bardarson B, Kudenchuk P, Baker A, Christenson J, Idris A, Davis D, Fabian TC, Aufderheide TP, Callaway C, Williams C, Banek J, Vaillancourt C, van Heest R, Sopko G, Hata JS, Hoyt DB, ROC Investigators. Out-of-hospital hypertonic resuscitation following severe traumatic brain injury: a randomized controlled trial. JAMA. 2010;304(13):1455-64.

16. Bulger EM, May S, Kerby JD, Emerson S, Stiell IG, Schreiber MA, Brasel KJ, Tisherman SA, Coimbra R, Rizoli S, Minei JP, Hata JS, Sopko G, Evans DC, Hoyt DB, ROC Investigators. Out-of-hospital hypertonic resuscitation after traumatic hypovolemic shock: a randomized, placebo controlled trial. Annals of Surgery. $2011 ; 253(3): 431-41$

17. Chang FC, Harrison PB, Beech RR, Helmer SD. PASG: does it help in the management of traumatic shock? Journal of Trauma-Injury Infection \& Critical Care. $1995 ; 39(3): 453-6$. 
18. Cooper DJ, Myles PS, McDermott FT, Murray LJ, Laidlaw J, Cooper G, Tremayne AB, Bernard SS, Ponsford J, HTS Study Investigators. Prehospital hypertonic saline resuscitation of patients with hypotension and severe traumatic brain injury: a randomized controlled trial. JAMA. 2004;291(11):1350-7.

19. Garner AA, Mann KP, Fearnside M, Poynter E, Gebski V. The Head Injury Retrieval Trial (HIRT): a single-centre randomised controlled trial of physician prehospital management of severe blunt head injury compared with management by paramedics only. Emergency Medicine Journal. 2015;32(11):869-75.

20. Helm M, Schuster R, Hauke J, Lampl L. Tight control of prehospital ventilation by capnography in major trauma victims. British Journal of Anaesthesia. $2003 ; 90(3): 327-32$

21. Junger WG, Rhind SG, Rizoli SB, Cuschieri J, Baker AJ, Shek PN, Hoyt DB, Bulger EM. Prehospital hypertonic saline resuscitation attenuates the activation and promotes apoptosis of neutrophils in patients with severe traumatic brain injury. Shock. 2013;40(5):366-74.

22. Maningas PA, Mattox KL, Pepe PE, Jones RL, Feliciano DV, Burch JM. Hypertonic saline-dextran solutions for the prehospital management of traumatic hypotension. American Journal of Surgery. 1989;157(5):528-33.

23. Mattox KL, Bickell W, Pepe PE, Burch J, Feliciano D. Prospective MAST study in 911 patients. Journal of Trauma-Injury Infection \& Critical Care. 1989;29(8):1104-11.

24. Mattox KL, Maningas PA, Moore EE, Mateer JR, Marx JA, Aprahamian C, Burch JM, Pepe PE. Prehospital hypertonic saline/dextran infusion for post-traumatic hypotension. The U.S.A. Multicenter Trial. Annals of Surgery. 1991;213(5):482-91. 
25. Moore EE, Johnson JL, Moore FA, Moore HB. The USA Multicenter Prehosptial Hemoglobin-based Oxygen Carrier Resuscitation Trial: scientific rationale, study design, and results. Critical Care Clinics. 2009;25(2):325-56. 26. Morrison LJ, Baker AJ, Rhind SG, Kiss A, MacDonald RD, Schwartz B, Perreira T, Simitciu M, Trompeo A, Black SE, Stuss DT, Rizoli SB. The Toronto prehospital hypertonic resuscitation--head injury and multiorgan dysfunction trial: feasibility study of a randomized controlled trial. J Crit Care. 2011;26(4):363-72. 27. Rhee KJ, O'Malley RJ. Neuromuscular blockade-assisted oral intubation versus nasotracheal intubation in the prehospital care of injured patients. Annals of Emergency Medicine. 1994;23(1):37-42.

28. Sayre MR, Daily SW, Stern SA, Storer DL, van Loveren HR, Hurst JM. Out-ofhospital administration of mannitol to head-injured patients does not change systolic blood pressure. Academic Emergency Medicine. 1996;3(9):840-8.

29. Schreiber MA, Meier EN, Tisherman SA, Kerby JD, Newgard CD, Brasel K, Egan D, Witham W, Williams C, Daya M, Beeson J, McCully BH, Wheeler S, Kannas D, May S, McKnight B, Hoyt DB, ROC Investigators. A controlled resuscitation strategy is feasible and safe in hypotensive trauma patients: results of a prospective randomized pilot trial. The Journal of Trauma and Acute Care Surgery. $2015 ; 78(4): 687-95$.

30. Turner J, Nicholl J, Webber L, Cox H, Dixon S, Yates D. A randomised controlled trial of prehospital intravenous fluid replacement therapy in serious trauma. Health Technology Assessment. 2000;4(31):1-57.

31. Vassar MJ, Perry CA, Gannaway WL, Holcroft JW. 7.5\% sodium chloride/dextran for resuscitation of trauma patients undergoing helicopter transport. Archives of Surgery. 1991;126(9):1065-72. 
32. Vassar MJ, Fischer RP, O'Brien PE, Bachulis BL, Chambers JA, Hoyt DB, Holcroft JW. A multicenter trial for resuscitation of injured patients with $7.5 \%$ sodium chloride. The effect of added dextran 70. The Multicenter Group for the Study of Hypertonic Saline in Trauma Patients. Archives Of Surgery. 1993;128(9):1003-11. 33. Vassar MJ, Perry CA, Holcroft JW. Prehospital resuscitation of hypotensive trauma patients with $7.5 \% \mathrm{NaCl}$ versus $7.5 \% \mathrm{NaCl}$ with added dextran: a controlled trial. Journal of Trauma-Injury Infection \& Critical Care. 1993;34(5):622-32.

34. Watts DD, Roche M, Tricarico R, Poole F, Brown JJ, Jr., Colson GB, Trask AL, Fakhry SM. The utility of traditional prehospital interventions in maintaining thermostasis. Prehospital Emergency Care. 1999;3(2):115-22.

35. Whitehead L, Perkins GD, Clarey A, Haywood KL. A systematic review of the outcomes reported in cardiac arrest clinical trials: The need for a core outcome set. Resuscitation. 2015;88:150-7.

36. Bhangu A, Singh P, Pinkney T, Blazeby JM. A detailed analysis of outcome reporting from randomised controlled trials and meta-analyses of inguinal hernia repair. Hernia. 2015;19(1):65-75.

37. Hoffman K, Cole E, Playford ED, Grill E, Soberg HL, Brohi K. Health Outcome after Major Trauma: What Are We Measuring? PLOS ONE. 2014;9(7):e103082.

38. World Health Organisation. International Classification of Functioning, Disability and Health: ICF: World Health Organisation, Geneva. 2001.

39. Williamson PR, Altman DG, Bagley H, Barnes KL, Blazeby JM, Brookes ST, Clarke M, Gargon E, Gorst S, Harman N, et al, Kirkham JJ, McNair A, Prinsen CAC,

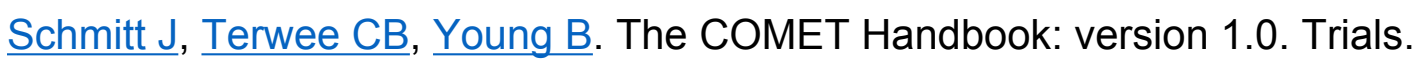
2017;18(Suppl 3):280. 
40. NHS Digital. Patient Reported Outcome Measures (PROMS). 2018. Available from: https://digital.nhs.uk/data-and-information/data-tools-and-services/dataservices/patient-reported-outcome-measures-proms Accessed 31 May 2018. 41. Ringdal KG, Coats TJ, Lefering R, Di Bartolomeo S, Steen PA, Røise O, Handolin L, Lossius HM. The Utstein template for uniform reporting of data following major trauma: A joint revision by SCANTEM, TARN, DGU-TR and RITG. Scandinavian Journal of Trauma, Resuscitation and Emergency Medicine. 2008;16(1):7.

42. Lockey DJ. Research questions in pre-hospital trauma care. PLOS Medicine. 2017;14(7):e1002345.

43. Gabbe BJ, Williamson OD, Cameron PA, Dowrick AS. Choosing outcome assessment instruments for trauma registries. Academic Emergency Medicine. $2005 ; 12(8): 751-8$

44. Cameron PA, Gabbe BJ, McNeil JJ. The importance of quality of survival as an outcome measure for an integrated trauma system. Injury. 2006;37(12):1178-84. 45. The Trauma Audit \& Research Network. Developing effective care for injured patients through process and outcome analysis and dissemination. The first decade: 1990-2000. Salford, England: 2001.

46. Sleat GKJ, Ardolino AM, Willett KM. Outcome measures in major trauma care: a review of current international trauma registry practice. Emergency Medicine Journal. 2011;28(12):1008-12.

47. Sprague S, Leece P, Bhandari M, Tornetta P, Schemitsch E, Swiontkowski MF. Limiting loss to follow-up in a multicenter randomized trial in orthopedic surgery. Controlled Clinical Trials. 2003;24(6):719-25. 
48. University of Birmingham. Centre for Patient Reported Outcome Research (CPROR). 2018. Available from:

https://www.birmingham.ac.uk/research/activity/mds/centres/cpror/index.aspx Accessed 31 May 2018.

49. Williamson PR, Altman DG, Blazeby JM, Clarke M, Devane D, Gargon E, Tugwell P. Developing core outcome sets for clinical trials: issues to consider. Trials. 2012;13(1):132.

50. Boers M, Kirwan JR, Wells G, Beaton D, Gossec L, d'Agostino M-A, Conaghan PG, Bingham CO, III, Brooks P, Landewé R, March L, Simon LS, Singh JA, Strand V, Tugwell P. Developing Core Outcome Measurement Sets for Clinical Trials: OMERACT Filter 2.0. Journal of Clinical Epidemiology.67(7):745-53.

51. Whitehead L, Perkins G, Haywood K. Towards a core outcome set for cardiac arrest clinical trials (COSCA): An international Delphi survey. Resuscitation. 2015;96:110. 


\section{FIGURE LEGENDS}

Fig 1. PRISMA diagram of search results

Fig 2. Outcome categories shown in rank order according to the Patient and Public Involvement group consensus, with median individual ranks also illustrated (interquartile ranges are shown as horizontal bars around the median) 